\title{
Trace elements and REY in bottom seawater and oxic pore water in NE Pacific: pilot study on the application of a DGT passive sampling method
}

\author{
KATJA SCHMIdT ${ }^{1}$ SOPHIE PAUL ${ }^{2}$ CORnElia KRIETE \\ ${ }^{1}$ German Federal Institute for Geosciences and Natural \\ Resources, 30655 Hannover, Germany \\ (*correspondence: katja.schmidt@bgr.de) \\ 2 Jacobs University Bremen, 28759 Bremen, Germany
}

Sampling and analysis of trace elements in open seawater and in sediment pore water in the deep sea is challenging due to small sample volumes and matrix effects. Here we evaluate an alternative method using the technique of diffusive gradients in thin films (DGT passive samplers), focussing on $\mathrm{Mn}, \mathrm{Cu}, \mathrm{Ni}, \mathrm{Pb}, \mathrm{V}, \mathrm{Cd}$, and rare earth elements and yttrium (REY). Sampling was performed in bottom seawater 5-10 meters above seafloor and in surface sediments in the German licence area for manganese nodule exploration in the Clarion Clipperton Zone. DGT data for seawater show PAASnormalized REY pattern typical for the total dissolved $(<0.2 \mu \mathrm{m})$ fraction, with increase from light to heavy REY, a strong negative Ce anomaly, a kink from Gd to $\mathrm{Tb}$, and a pronounced positive $\mathrm{Y} / \mathrm{Ho}$ anomaly. Calculated concentrations of REY as well as $\mathrm{Mn}, \mathrm{Cd}$, $\mathrm{V}, \mathrm{Ni}$ agree very well with data reported for $0.2 \mu \mathrm{m}$ filtered Pacific deep seawater in this area, indicating that these elements are almost completely labile-bound. Sediment DGT sticks deployed in cores taken with a multicorer provide in situ high-resolution profiles of trace metal fluxes in the first $15 \mathrm{~cm}$ of the sediment. We observe altered PAAS-normalized REY patterns with MREE enrichment, and a strong correlation of REY and Mn concentration. The DGT passive sampling method provide an additional tool to investigate biogeochemical processes at the deep-sea sediment-water interface and in the open ocean, and to monitor effects of anthropogenic disturbances at the seafloor on benthic trace element fluxes. 